\title{
Sub Clinical Disease Presenting with Serious Clinical Manifestations - Blame Thyroid
}

\author{
Dhruv Talwar¹, Sunil Kumar², Amrutha Garikapati³ , Anuj Chaturvedi
}

\begin{abstract}
${ }^{1}$ Department of Medicine, Jawaharlal Nehru Medical College, Datta Meghe Institute of Medical Sciences (Deemed to Be University), Sawangi, Wardha, Maharashtra, India. ${ }^{2}$ Department of Medicine, Jawaharlal Nehru Medical College, Datta Meghe Institute of Medical Sciences (Deemed to Be University), Sawangi, Wardha, Maharashtra, India. ${ }^{3}$ Department of Medicine, Jawaharlal Nehru Medical College, Datta Meghe

Institute of Medical Sciences (Deemed to Be University), Sawangi, Wardha, Maharashtra, India. ${ }^{4}$ Department of Medicine, Jawaharlal Nehru Medical College, Datta Meghe Institute of Medical Sciences (Deemed to Be University), Sawangi, Wardha, Maharashtra, India.
\end{abstract}

\section{INTRODUCTION}

Graves' disease is responsible for 60 to $80 \%$ cases of thyrotoxicosis and characteristically presents between the ages of 20 and 50 years. Both environmental and genetic factors lead to the development of Grave's Disease.(1) Hyperthyroidism seen in grave's disease is caused by thyroid-stimulating immunoglobulins (TSI) that are synthesized in the thyroid gland, bone marrow and lymph nodes, and detected by direct bioassays or TSH-binding inhibiting immunoglobulin (TBII) assays. Thyroid peroxidase (TPO) antibodies are found in about $80 \%$ of cases suggestive of Grave's Disease.(1) Grave Disease is known to have multiple serious complications like Hypokalemia, Thrombocytopenia, heart rhythm abnormalities, brittle bone and thyroid storm(1,2). Hypokalemia in Grave's Disease is a rare life-threatening complication seen, mostly in young males, often presents acute onset paraparesis. Paralytic symptoms usually occur after heavy exercise or carbohydrates rich meal.(3)

This case report highlights about a young man who presented with quadriparesis, later on investigation diagnosed as hypokalemia due to subclinical grave's disease.

Clinically silent Grave's Disease presenting with neurological quadriparesis is diagnostic challenge. Neurological paresis rapidly resolves with correction of hypokalemia. This report discusses the case of young man who presented with acute onset quadriparesis without any clue, came out as hypokalemic due to subclinical grave's disease.

\section{PRESENTATION OF CASE}

A 28 years old male presented in the OPD of Department of Medicine with the complaints of generalized weakness with inability to move all four limbs and difficulty in walking for 1 day. There was no history of exposure to heat or consumption of high carbohydrate diet. No history of nausea / vomiting or fever was present. There was no history of weight loss, heat intolerance, or loose stools.

There was no history of hypertension, diabetes mellitus, or pulmonary tuberculosis. Patient was a chronic alcoholic since past 10 years and last intake was 2 days prior to admission.

Patient was of average build, and not in distress. Blood pressure was 120/80 mmHg; pulse was $76 / \mathrm{min}$, regular; respiratory rate was $22 /$ min and $\mathrm{SpO}_{2}$ was $97 \%$ on room air. Examination of head and neck was normal. Single breath count was 35 (normal $>30$ ). Systemic examination of chest, cardiac and abdomen was normal. Nervous system examination revealed conscious and oriented patient, power was decreased in all four limbs $(2 / 5$ in all four limbs) and all the deep tendon reflexes were absent. Both planters were flexors. Examination of sensory system was normal. All cranial nerves were normal.
Corresponding Author:

Sunil Kumar,

Department of Medicine,

Jawaharlal Nehru Medical College, Datta Meghe Institute of Medical Sciences (Deemed to Be University),

Sawangi, Wardha, Maharashtra, India

Sawangi (M), Wardha, Maharashtra, India.

E-mail: sunilkumarmed@gmail.com

DOI: $10.14260 / \mathrm{jemds} / 2020 / 518$

How to Cite This Article:

Talwar D, Kumar S, Garikapati A, et al. Sub clinical disease presenting with serious clinical manifestations- blame thyroid. J Evolution Med Dent Sci 2020;9(33):23922393, DOI: 10.14260/jemds/2020/518

Submission 14-05-2020,

Peer Review 06-07-2020,

Acceptance 14-07-2020,

Published 17-08-2020.

Copyright (c) 2020 JEMDS. This is an open access article distributed under Creative Commons Attribution License [Attribution 4.0 International (CC BY 4.0)] 
Laboratory investigations showed Hb 16.1 gm/dL, MCV 91, platelet count: 245000/cumm, WBC: $12100 / \mathrm{dL}$, urea: 17 $\mathrm{mg} / \mathrm{dL}$, creatinine: $0.7 \mathrm{mg} / \mathrm{dL}$, sodium $145 \mathrm{meq} / \mathrm{L}$, alkaline phosphatase: $121 \mathrm{U} / \mathrm{L}, \mathrm{ALT}: 34 \mathrm{U} / \mathrm{L}, \mathrm{AST}: 32 \mathrm{U} / \mathrm{L}$, albumin: 3.9 $\mathrm{gm} / \mathrm{dL}$, globulin $3.5 \mathrm{gm} / \mathrm{dL}$, total protein $7.5 \mathrm{gm} / \mathrm{dL}$, total bilirubin: $0.6 \mathrm{mg} / \mathrm{dL}$, conjugated bilirubin: $0.5 \mathrm{mg} / \mathrm{dL}$ and unconjugated bilirubin: $0.1 \mathrm{mg} / \mathrm{dL}$.

Routine chest $\mathrm{X}$ ray and EKG were normal. However, serum potassium was markedly low $(2.0 \mathrm{mEq} / \mathrm{L}$; normal $3.5-5.5$ $\mathrm{mEq} / \mathrm{L}$ ) and Free T3 was $8.71 \mathrm{pg} / \mathrm{mL}$ (normal: 2.77 to 5.27 $\mathrm{pg} / \mathrm{mL}$ ), Free T4 was $4.06 \mathrm{ng} / \mathrm{dL}$ (normal 0.78 to $2.19 \mathrm{ng} / \mathrm{dL}$ ) and TSH was $0.015 \mathrm{mIU} / \mathrm{L}$ (normal: $0.4-4.00 \mathrm{mIU} / \mathrm{L}$ ). Nerve conduction test was suggestive of sensory motor polyneuropathy. MRI of brain and cervical spine was done and was normal. Due to low TSH, Anti Microsomal Antibody (AMA) and TSH receptor antibody was planned which was very much high as $949.2 \mathrm{IU} / \mathrm{mL}$ and $9.81 \mathrm{IU} / \mathrm{L}$ ), Suggestive of subclinical Grave's Disease, as patient had no any symptoms of hyperthyroidism.

Patient was treated on intravenous KCL and potassium levels were corrected which led to dramatic improvements in patient's symptoms and he regained power of 5/5 in all four limbs in next 24 hours. Patient was further managed for Grave's Disease with neomercazole and propranolol and is doing well on follow up.

\section{DISCUSSION}

Hypokalaemia due to Grave's Disease is characterized by muscular weakness which is transient and may vary from mild to complete flaccid paralysis with intact sensory and bladder, bowel functions. Generally upper limbs are spared or less affected and in our case all four limbs were affected and presented with acute quadriparesis rather than paraparesis. Also, proximal muscles are more severely affected than distal muscles as seen in our case too.(3)

HLA A2 Bw22 and Aw19 B17 increase the chances of developing this disease. ${ }^{[2]}$ Attack Frequency varies from yearly to every few days or even every few hours and it's always difficult to diagnose when seen first time with no past history of similar attacks as in our case.

Factors that are known to precipitate HHP are increased intake of salt and carbohydrate, unaccustomed exercise, surgery, trauma, exposure to cold, alcohol, drugs like diuretics or severe emotional stress. ${ }^{[4,5]}$ Deep tendon reflexes are diminished accompanied with hypotonia.

Basic pathophysiology is development of hypokalemia due to increased activity of sodium potassium adenosine thiophosphate pump secondary to increased thyroid hormone levels leading to intracellular shift of potassium and development of hypokalemia which manifests as generalized muscular paralysis but spares diaphragm and ocular muscles. However, decrease in activity of skeletal muscle calcium channels has also been reported. $[4,5]$

Grave's Disease also leads to increased responsiveness of beta adrenergic receptor responsiveness contributing to increased activity of $\mathrm{Na}^{+}, \mathrm{K}^{+}$and ATPase channels and this may also explain role of beta blockers in prevention of hyperadrenergic state during exercise in precipitating hypokalemic attacks[4]. Also, hyperinsulinemia may be seen in some patients leading to attacks after heavy meals. Sudden onset quadriparesis sets in differential diagnosis of the following conditions such as acute Transverse myelitis, Electrolyte abnormalities of sodium, calcium, potassium and magnesium, Guillen Barre syndrome and Myopathies.[5]

\section{CONCLUSIONS}

This case highlights that though hypokalemia caused by hyperthyroid disease (very rare in grave's disease) is a wellknown and well-described clinical complication, yet is frequently missed, misdiagnosed or there is a delay in diagnosis due to conflicting signs and symptoms (no or minimal symptoms of Grave's while muscular paralysis is profound).

Financial or Other Competing Interests: None.

\section{REFERENCES}

[1] Kashyap A, Kashyap S. Young male with recurrent flaccid quadriparesis and complete recovery. Postgrad Med J 2000; 76(896):373-7.

[2] Lam L, Nair RJ, and Tingle L. Thyrotoxic periodic paralysis. Proc (Bayl Univ Med Cent) 2006; 19(2):126-9.

[3] Neki NS. Hyperthyroid hypokalemic periodic paralysis. Pak J Med Sci 2016; 32(4):1051-2.

[4] Kumar S, Diwan S, Chandek S, et al. Subdural hematoma in Grave's disease induced thrombocytopenia. Online J Health Allied Sci 2012; 11(4):17.

[5] Mellgren G, Bleskestad IH, Aanderud S, et al. Thyrotoxicosis and paraparesis in a young woman: case report and review of the literature. Thyroid 2002; 12(1):77-80. 